\title{
Gene expression and mental disease ${ }^{1}$
}

The structure and function of an organ such as the brain depends largely upon its constituent cells and the pattern of proteins which they synthesize; this in turn results from the expression of specific genes within each cell (Milner et al. 1987). Given that all human cells contain the same genetic material, differences in cell phenotypes depend upon mechanisms which result in expression or suppression of particular genes and production or absence of particular proteins both during development and in response to stimuli of various kinds. Thus, although recombinant DNA techniques and gene sequencing are of great importance (Baron \& Rainer, 1988), the study of normal and abnormal regulation of gene expression and protein synthesis plays a significant complementary role. Of particular relevance to psychiatry are processes occurring in neurons and glia, for example the production of enzymes, transmitters and receptors, and how these processes may be affected in neuropsychiatric disease. The advent of new experimental methods has already led to advances in understanding normal and pathological forms of gene expression in the brain, and their application to psychiatry has rapidly become apparent. We attempt to cover the ground prepared by Owen \& Whatley (1988), who concluded their review of molecular genetics in mental disease by stating 'from here we may hope to follow the sequence of changes that finally results in phenotype, so preparing the ground for more rational and effective therapeutic strategies'.

\section{FROM GENE TO PRO'TEIN}

The two-step process by which a gene is first transcribed into messenger RNA (mRNA) followed by translation of the mRNA into a protein is now recognized to consist of multiple smaller steps, each representing a potential site for regulation or defect.

The primary event in expressing a gene is initiation of transcription, which involves alteration in the DNA configuration at the site of the gene, and a number of initiation factors, recognition sequences and enzymes which combine to produce heterogeneous nuclear RNA ('immature' mRNA). Control of this step is not surprisingly under a number of regulatory influences (Darnell, 1982; Lewin, 1985; Ptashne, 1988; Schlief, 1988); the growing mRNA and its termination are also subject to control (Yanofsky, 1988). Newly transcribed nuclear RNA consists of sequences of base pairs coding for the protein, called exons, separated by non-coding sequences, called introns, together with a length of non-coding bases at each end; the non-coding regions are thought to play another regulatory role. Prior to translation, RNA undergoes modification: a methylated cap is added to the 5 ' end, and a length of adenosine residues (the 'poly $A$ tail ') to the 3 ' end. The introns are then excised and the exons spliced together to leave the gene as an uninterrupted linear sequence, which, complete with non-coding ends, cap and tail, is ready to be translated ('mature' mRNA). To complicate the story, for some genes, variations in the position where the introns are excised, a process called alternative splicing, enables one precursor mRNA to generate different mature mRNAs, resulting in more than one protein product (Breitbart et al. 1987).

After migration into the cytoplasm and attachment to a ribosome, synthesis of the amino-acid chain begins, involving ribosomal and transfer RNA and another series of regulatory molecules (Lewin, 1985). The peptides may then undergo post-translational modification such as phosphorylation or glycosylation before arriving at their final conformation and destination (Magee \& Hanley, 1988). Each mRNA molecule gives rise to a variable number of protein copies prior to degradation by ribonuclease. Messenger RNA half-life depends partly on the poly A tail

' Address for correspondence: Dr P. J. Harrison, Department of Anatomy and Cell Biology, St Mary's Hospital Medical School, Norfolk Place, London W2 IPG.

30 
which protects it from this enzyme, and control of the tail may itself be an important regulatory step (Hunt, 1988).

The above processes and constraints appear to occur in all cells. In addition, the brain has a number of tissue-specific mechanisms controlling gene expression (Sutcliffe, 1988). This is made necessary by the dedication of a third of the genome to brain mRNA, and the variety of mRNAs expressed compared to other tissues, reflecting both the overall level of complexity and the differentiation of cell types in the brain. One set of candidates for allowing a gene to be expressed exclusively in the brain are identifier sequences (Milner et al. 1987, but see Chikharaishi, 1986). Another brain-specific mechanism is the use of non-adenylated mRNA (poly (A)-mRNA): as mentioned, most mRNAs receive a poly $\mathrm{A}$ tail, but the brain contains a population of poly (A)mRNA, thought to be important in development (Chaudhari \& Hahn, 1983). However, technical problems make their identification difficult, and as with other tissue-specific mechanisms they remain poorly understood. This is also true for the ways in which the intracellular processes described above are influenced by external events - a crucial stage in relating molecular biology to clinical psychiatry.

\section{STUDY OF BRAIN GENE EXPRESSION}

A corollary of the complexity of brain gene expression is that multiple experimental techniques are needed to investigate it. Moreover, until gaps in understanding the sequence of events from gene to protein are filled, certain assumptions may have to be made as to how changes detected at one point in the process affect others. However, there are now a number of techniques available for investigating different steps on the gene-to-protein pathway which together promise to be of considerable value.

Identification and sequencing of normal and abnormal genes using molecular genetics is providing fundamental information relevant to psychiatric disorders (Owen \& Whatley, 1988; Baron \& Rainer, 1988). For inherited conditions such as Huntington's chorea this approach is the key to understanding the causation of the disease, and even for multifactorial and polygenic disorders it will be a major advance to locate linked genes which may be of aetiological significance. However, it is unlikely that the function of an encoded protein will be apparent from its gene, and studies of the expression of a gene through to the structure, role and fate of its protein are necessary to help explain how a genetic abnormality results in the clinical picture. While awaiting the identification of linked genes to study, the techniques described below can also be used to investigate how abnormalities in the processing of various genes gives rise to disease pathology. For example, in Alzheimer's disease (AD), alterations in the cholinergic system are unlikely to have a primary causal role (Harrison, 1986) but contribute to the clinical deficits of the disorder (Perry, 1988). Gene expression studies can help clarify the nature of the cholinergic loss and its role in producing the clinicopathological picture of AD. Furthermore, some neuropsychiatric disorders are unlikely to have a major genetic component (e.g. Parkinsonian dementia), and in these cases study of the expression of various genes is likely to be the primary focus, rather than a genomic analysis.

Until recently, little was known of the links between genes in the brain and the functioning of brain proteins revealed by neurochemical studies. The advent of several molecular neurobiological techniques is beginning to bridge this gap. Northern blotting uses extracted, purified RNA and separates the different mRNA species by size. Following transfer of the RNA from electrophoretic gel to filter paper, specific mRNAs can be detected by hybridization with a labelled complementary sequence. Patterns of RNA distribution (analagous to the DNA fingerprints made by Southern blotting) are produced and can be compared qualitatively and quantitatively between brain regions or between normal and disease brains (Crapper McLachlan et al. 1988). In vitro translation tests the functional integrity of mRNA by its ability to give rise to protein, an ability which might be impaired in disease (Gilbert et al. 1981; Octave et al. 1988). This technique can be used in association with two-dimensional protein electrophoresis to assess the nature and quantity of the resultant protein; differences in translation products in various circumstances can thereby be 
investigated (Guillemotte et al. 1986; Perrett et al. 1988). A third method based on extracted brain mRNA is that of cDNA libraries, whereby an mRNA (and thus an expresssed gene) is used to produce its complementary DNA (cDNA) fragment (Milner et al. 1987; Baron \& Rainer, 1988). The cDNA can then be sequenced and identified, translated in an appropriate vector, or used as a probe to determine where that particular mRNA is present in another brain region or in a diseased brain (Octave et al. 1988). The use of multiple cDNA probes gives a screening method by which mRNAs may be found to be unexpectedly absent (or present) in different situations. Attention can then focus on such mRNAs as representing potential disease associated alterations. This method of 'subtractive cloning' can also be applied to the study of drug-induced effects on gene expression (Friedman et al. 1984) and help distinguish these from disease-specific changes.

In contrast to the above techniques, which are limited to regional or whole brain analyses, in situ hybridization histochemistry (ISHH) enables gene expression to be investigated at the cellular level, and thus provides a more detailed and localized understanding of gene expression processes. As in Northern blotting, ISHH uses a labelled length of DNA or RNA as a probe to hybridize to, and thus detect, a complementary mRNA strand coding for a particular protein, but within tissue sections (Valentino et al. 1987). Cloned cDNAs or their RNA transcription products can be used as probes. Alternatively, synthetic probes can be directed against parts of any gene whose base sequence is known or can be deduced from the amino-acid sequence of its protein. Neuropsychiatric applications of ISHH use 10-20 micron brain sections, and permit gene expression to be studied in individual neurons and glia, and correlated with a number of other parameters. For example, ISHH, which identifies the cell bodies (and possibly dendrites) synthesizing a protein, can be compared to immunocytochemical or autoradiographic localization of that protein. Because proteins may be transported along neuronal processes to distant sites, the two techniques give complementary information: ISHH identifies the cells making an mRNA at a particular time, whereas immunocytochemistry establishes the distribution of the protein product. Comparison of results obtained with these different methods may also yield information on the turnover of individual proteins. ISHH can be related to known morphological features such as cortical laminae or cell types, or to pathological features, for example neurofibrillary tangles and senile plaques in AD, discussed below. ISHH on thin serial sections allows two (or more) mRNAs to be studied in the same cell, and expression of how genes are co-regulated can be investigated. The amount of hybridization in a cell can be determined and is proportional to the level of mRNA present; as a result, quantitative estimates of expression of a gene can be made. However, it is unclear to what extent mRNA levels are an indication of rates and amounts of protein synthesis, the latter being affected by many other factors. As a rule, changes in protein synthetic rates are preceded by an equivalent change in mRNA levels due to altered transcription rates (Marotta et al. 1986), but exceptions exist. For example, beta-tubulin synthesis is regulated by changes in the stability of its mRNA (Yen et al. 1988), and other genes may also be regulated post-transcriptionally.

On a practical note, mRNA is surprisingly stable post mortem, and permits human autopsy tissue to be used for gene expression studies (Sadjel-Sulkowska \& Marotta, 1984; Johnson et al. 1986). This stability compares favourably with requirements for neurochemical research (Perry et al. 1982), and means that tissue availability need not be a major problem. Conversely, agonal state markedly affects measures of protein synthesis, and must be controlled for (Gilbert et al. 1981; Johnson et al. 1986; Perrett et al. 1988). Other non-specific influences on gene expression which need to be distinguished from those caused directly by a disease include aging and medication (Marotta et al. 1986).

Studies of DNA and RNA as outlined above can be combined with established neurochemical and neuropharmacological methods, which in effect are studying the end results of all the preceding processes. Disease-related changes in levels and activities of enzymes and receptors detected by assay, ligand binding and autoradiography, for example, may be due to alterations at any step. It may prove that the primary defect in a particular protein is not with the gene or its expression, but in its post-translational modification or as a result of changes in the cellular environment. Examples of this kind (e.g. increased phosphorylation) will be approached best by standard biochemical 
techniques, as genomic and transcriptional analysis will not reveal any abnormality. Conversely, where initial studies suggest the defect lies in the gene itself (e.g. a mutation) or in its transcription (e.g. aberrant splicing), molecular neurobiological techniques will be of particular value. Ultimately, only by investigating at a number of points and by correlations between each approach will specific defects be located, and their many consequences be understood. Advances will also be promoted by technical developments which increase sensitivity and permit other steps on the gene expression pathway to become accessible. Most importantly, sustained and integrated research programmes will be essential given the great molecular complexity of the brain, both in terms of its normal processes and their disruption in disease states.

\section{NEUROPSYCHIATRIC APPLICATIONS}

\section{Alzheimer's disease}

Although in the long-term psychiatry may benefit from understanding of gene expression in a number of ways, including its role in brain development, the most immediate clinical relevance comes from the study of changes in gene expression as part of the disease process. In this as in other respects, $A D$ is the paradigm condition. This is due both to the availability of tissue from patients and age-matched controls, and because of the known morphological and biochemical changes with which gene expression studies can be correlated. Within AD, amyloid has been the focus of much recent research and is taken as an example of the application of this field to psychiatry.

The amyloid gene became of interest for two reasons. First, amyloid is a key feature of AD, being a major constituent of senile plaques and being deposited around blood vessels. Second, the finding that its gene is located on chromosome 21 (see Owen \& Whatley, 1988) fitted in with the occurrence of $\mathrm{AD}$ in trisomy 21 ; this suggested that an abnormality or over-expression of the amyloid gene (such as triplication) might account for the amyloid deposition seen in AD, and that this in turn was a major pathogenic step: precipitation of excess or abnormal amyloid might be the cause for the neuronal degeneration and resultant pathological changes.

The story has not proved to be so simple. The AD gene is now known not to be triplicated in AD (St George Hyslop et al. 1987; Tanzi et al. 1987; Podlinsky et al. 1987) and is probably normal in structure. Attention has therefore switched to defects in its expression to explain the amyloidosis. ISHH studies have shown that expression of the amyloid gene occurs in neurons throughout life and is not restricted either to AD cases or to brain regions affected by AD (Bahmanyar et al. 1987; Goedert, 1987); localization of amyloid expression to neurons rather than glia was also confirmed by this work. The implication is that amyloid gene expression may be a necessary, but is not a sufficient, explanation for AD amyloid, with implications for pathogenic theories involving it (Lewis et al. 1988). Moreover, total brain amyloid expression is normal in AD, although certain cell populations, such as neurons in the basal nucleus (Cohen et al. 1988) and entorhinal cortex (Higgins et al. 1988) do show increased amyloid mRNA levels. Hybridization with probes detecting different parts of the amyloid precursor protein mRNA have demonstrated alterations in the splicing of the gene in $\mathrm{AD}$ compared to controls, with reduced production of a component which codes for a protease inhibitor (Palmert et al. 1988). In consequence, there is current speculation as to the role of increased protease activity in AD pathogenesis (Carrell, 1988). In addition to such transcriptional changes, post-translational modification by excess phosphorylation is also under investigation (Gandy et al. 1988). If the defect in AD amyloid is indeed at the mRNA level or beyond, it emphasizes the need to study all points between genotype and phenotype when attempting to account for a particular clinical or pathological feature of a disease. Finally, the amyloid protein is being mapped in the brain using monoclonal antibodies directed against various parts of the molecule, and identified in discrete cell populations (Majocha et al. 1988). These can then be related to neuronal groups defined by other parameters such as connectivity (Pearson et al. 1985), transmitter type (Bowen, 1988) or antigenic properties (Miller et al. 1987).

There are other genes which deserve attention in AD and which could be investigated in a similar fashion to amyloid. Nerve growth factor (NGF) is one example, as it is needed to sustain central 
cholinergic neurons (Rennert \& Heinrich, 1986), which are heavily affected in AD, and NGF levels decline with normal ageing (Larkfors et al. 1987). Second messenger systems, including G proteins and protein kinases are also of interest (Worley et al. 1987), as changes therein might be a common mechanism to explain the various transmitter alterations occurring in AD. A final example is the study of structural proteins such as tubulin and tau, in view of the marked involvement of the cytoskeleton in AD (Anderton, 1988). In all cases, interpretation of changes in expression of specific genes must take into account the significant reduction in total mRNA levels and rates of protein synthesis seen in AD (Marotta et al. 1986). In this respect, it will be valuable to identify genes whose expression does not change in parallel to the overall decline, but which either falls more precipitously or remains relatively preserved (Crapper McLachlan et al. 1988). The overall reduction in gene expression may be due to loss of neurons and reduced demand as well as to impaired transcription and increased RNA degradation (Marotta et al. 1986), although the relationship of widespread neuronal sickness to disease pathogenesis is unclear (Mann et al. 1981) and is another target for study.

\section{Other mental disorders}

The above techniques can also be fruitfully applied to other mental disorders, though as yet there is little data. In schizophrenia and bipolar depression, for example, demonstration of changes in gene expression of monoaminergic enzymes, transmitters or receptors would complement the known neurochemical alterations in these proteins, and help to correlate them with the suspected structural changes in these disorders (Roberts, 1988; Jeste et al. 1988). As with AD, variation between cell populations, brain regions and hemispheres, as well as between psychotic and normal brains, deserves investigation. The major practical limitations will be to obtain sufficient brain tissue from a reasonably homogeneous clinical population, and to control for medication status (Reynolds, 1988). As the number of techniques relying on fresh post mortem material grows, together with the value of information gained from them, the development of methods for collection of brains becomes important. These should include detailed prospective evaluation of the patients - including standardized psychopathological and diagnostic descriptions, psychometry and laboratory investigations - to maximize the clinico-pathological correlations which can be made subsequently. Such collaborations will help prevent the compartmentalization of research and ensure that interested molecular biologists are directed towards clinically important problems.

\section{CONCLUSIONS}

Investigation of gene expression in the brain is likely to help significantly with the search for pathogenic factors producing psychiatric disease, although such optimism is tempered by the realization of the complexity of the underlying processes. With suitable resources, however, and in combination with the other approaches outlined above, a coherent picture should begin to emerge of the connection between molecular events in a neuron and a clinical syndrome. Molecular genetic methods are identifying the hereditary components of various disorders and at some stage will sequence the gene(s) which may be abnormal. Gene expression research plays a central role linking these and other findings to biochemical studies of the resultant structure and functioning of proteins. As well as helping clarify the pathogenic sequence, such studies may well point to sites of therapeutic manipulation more amenable than DNA-directed approaches and help avoid some of the ethical issues involved in altering the genetic blueprint.

Finally, the focus on molecular neurobiology should in no way preclude holistic medicine (Weatherall, 1987), and established views concerning factors important to mental health are not about to be replaced. Psychiatric problems will continue to result from psychosocial stresses as much as from alterations in the processing of genes, and both will require investigation and intervention. For the time being, however, these experimental approaches seem a profitable avenue to explore towards the common goal of better understanding and treatment of mental disease. Therefore, it is important that clinicians are aware of the technology available in this area and 
become involved both in the direction of research and in the assessment and collection of the material in order to maximize the contribution of these techniques to our knowledge of brain disease.

\section{P. J. HARRISON AND R. C. A. PEARSON}

\section{REFERENCES}

Anderton, B. H. (1988). Alzheimer's disease' parred helical filaments and the cytoskeleton. Nature 335, 497-498.

Bahmanyar, S. Higgins, G. A.. Goldgaber, D., Lewis, D. A., Morrison, J H., Wilson, M. C., Shankar, S. K. \& Gadjusek, D. C. (1987) Localization of amyloid beta proten messenger RNA in brains from patsents with Alzhelmer's disease. Sctence 237, 77-80.

Baron. M. \& Raner, J. D. (1988). Molecular genetucs and human disease - implicatıons for modern psychıatric research and practuce. Brush Journal of Psychiary 152, 741-753

Bowen. D. M. (1988). Neurotransmitters in Alzheımer's disease. Age 11. $104-110$

Breitbart, R. E . Andreadis. A \& Nadel-Gınard, B. (1987). Alternatuve splicing: a ubiquitous mechanısm for the generation of muluple protein isoforms from single genes. Annual Review of Biochemustr. 56, 467.495.

Carrell. R W. (1988). Alzheimer's disease: enter a protease inhibıtor. Nature 331, 478-479

Chaudharı, N. \& Hahn, W. E. (1983) Genetic expression in the developing brain. Science 220, 924-928.

Chıkharaıshi. D. M. (1986). The ID, brain identufier, model of neuronal gene expression: a re-evaluation. Trends in Neuroscience 9. $543-546$

Cohen. M. L. Golde, T. E., Usıak, M. F., Younkın, L H. \& Younkın. S. G. (1988). In situ hybridization of nucleus basalis neurons shows increased beta-amyloid mRNA in Alzheimer's disease. Proceedings of the National Academy of Sciences USA $\mathbf{8 5}$, $1227-1231$

Crapper McLachlan, D. R., Lukiw, W. J., Wong. L., Bergeron, C. \& Bech-Hansen. N. T. (1988). Selective messenger RNA reduction in Alzheimer's disease. Molecular Brain Research 3, 255-262.

Darnell. J. E. (1982). Variety in the level of gene control in eukaryotic cells. Nature 297. 365-371.

Friedman, R. L.. Manly, S. P. McMahon, M., Kerr, I. M. \& Stark, G. R. (1984) Transcriptional and posttranscriptional regulation of interferon-induced expression in human cells. Cell 38, 745-755.

Gandy. S., Czernik, A. J. \& Greengard, P. (1988). Phosphorylation of Alzheimer disease amyloid precursor peptide by protein kınase $\mathrm{C}$ and $\mathrm{Ca}++/$ calmodulin-dependent protein kinase 11 . Proceedings of the National Academy of Sciences USA 85, 62186221

Gilbert, J. M., Brown, B. A., Strocch,, P., Bird, E. D. \& Marotta, C. A. (1981). The preparation of brologically active mRNA from human post mortem brain tissue. Journal of Neurochemistry 36 976-984.

Goedert, M. (1987). Neuronal localızation of amyloid beta proteın precursor mRNA in normal human brain and in Alzheımer's disease. EMBO Journal 6, 3627-3632.

Guillemotte. J. G.. Wong, L., Crapper McLachlan, D. R. \& Lewis, P. N. (1986) Characterization of messenger RNA from the cerebral cortex of control and Alzheimer-afflicted brain. Journal of Neurochemustry 47, 987-997.

Harrison. P J. (1986). The pathogenesis of Alzheimer's disease. beyond the cholinergic hypothesis Journal of the Royal Society of Medrcine 79, 347-351

Higgins, G A., Lewis, D. A., Bahmanyar, S., Goldgaber, D.. Gadjusek. D. C.. Young, W G, Morrison, J. H. \& Wilson, M. C. (1988) Differential regulation of amylord-beta-protein mRNA expression within huppocampal neuronal subpopulations in Alzheimer disease. Proceedings of the National Academy of Scuences USA 85, 1297-1301

Hunt, T. (1988). Tubulin synthesis controlling mRNA lifespan. Nalure 334, 567-568.
Jeste, D. V., Lohr, J. B. \& Goodwin, F. K. (1988). Neuroanatomical studies of major affectuve disorders: a review and suggestions for further research. British Journal of Psychialry 153, 444-459.

Johnson, S. A., Morgan, D. G. \& Finch, C. E. (1986). Extensive post mortem stability of RNA from rat and human brain. Journal of Neuroscience Research 16, 267-280.

Larkfors, L., Ebendal, T., Whittemore, S. R., Persson, H., Hoffer, B. \& Olson, L (1987). Decreased level of nerve growth factor (NGF) and its messenger RNA in the aged rat brain. Molecular Bram Research 3, 55-60.

Lewin, B. (1985). Genes $I /$. Wiley. New York.

Lewis, D. A., Higgins, G. A., Young, W. G., Goldgaber, D. Gadjusek. D. C \& Wilson. M. C. (1988). Distribution of precursor amylord-beta-protein messenger RNA in human cerebral cortex : relationship to neurofibrillary tangles and neuritic plaques. Proceedings of the National Academy of Sciences USA 85, 1691-1695.

Magee, T. \& Hanley, M. (1988). Protein modification: sticky fingers and CAAX boxes. Nature 335, 114-115.

Majocha, R. E., Benes, F M., Reifel, J. L., Rodenrys, A. M. \& Marotta, C. A. (1988). Laminar-specific distribution and infrastructural detail of amyloid in the Alzheimer disease cortex visualized by computer-enhanced imaging of epitopes recognized by monoclonal antibodies Proceedings of the National Academy of Sciences USA 85, 6182-6186.

Mann, D. M. A., Neary, D., Yates, P. O., Lincoln, J., Snowden, J. $\mathrm{S} \&$ Stanworth, P. (1981). Alterations in protein synthetic capability of nerve cells in Alzheimer's disease Journal of Neurology, Neurosurgery and Psychiatry 44, 97102.

Marotta, C. A., Majocha, R E., Coughlın, J. F., Manz, H. J., Davies, P., Ventosa-Michelman, M., Chou, W.-G., Zain, S. B. \& Sajde!-Sulkowska, E. M. (1986). Transcriptional and translational regulatory mechanisms during normal aging of the mammalian brain and in Alzheimer's disease. Progress in Brain Research 70, 303-320.

Miller, C A, Rudnicka, M., Hinton, D. R., Blanks, J. C. \& Kozlowski, M. (1987). Monoclonal antibody identification of subpopulations of cerebral cortical neurons affected in Alzheimer disease. Proceedings of the National Academy of Sciences USA 84, 8657-8661.

Milner, R. J., Bloom, F. E. \& Sutcliffe, J. G. (1987). Brain-specıfic genes: strategies and issues. Current Topics in Developmental Biology 21, 117-150.

Octave, J. N., de Sauvage, F., Macq, A. F. \& Maloteaux, J. M. (1988). Cloning of the cDNA from normal brain and brain of patients with Alzheimer's disease in the expression vector lambda GT 11. Progress in Neuropsychopharmacology' and Biological Psychiatry 12, 813-820.

Owen, M. J., Whatley, S. J. (1988). Polymorphic DNA markers and mental disease. Psychological Medicine 18, 529-533.

Palmert, M. R., Golde, T. E., Cohen, M. L., Kovacs, D. M., Tanzı, R. E., Gusella, J. F., Usiak, M. F., Younkın, L. H. \& Younkin, S. G. (1988). Amyloid protein messenger RNAs: differential expression in Alzheimer's disease Science 241, 1080-1084.

Pearson, R. C. A., Esiri, M. M , Horns, R. W., Wilcock, G. K. \& Powell, T. P. S. (1985). Anatomical correlates of the pathological changes in the neocortex of Alzheimer's disease. Proceedings of the National Academy of Sciences USA 82, 4531-4534.

Perrett, C. W., Marchbanks, R. M. \& Whatley, S. A. (1988). Characterisation of messenger RNA extracted post-mortem from the brains of schizophrenic, depressed and control subjects. Journal of Neurology, Neurosurgery and Psychiatry 51, 325331. 
Perry. E. K. (1988). Acetylcholine and Alzheimer's disease. British Journal of Psychatry 152, 737-740.

Perry, E. K.. Perry, R. H. \& Tomlinson, B E (1982). The influence of agonal status on some neurochemical activities of post mortem human brain tissue. Neuroscience Letters 29, 303-307

Podlınsky, M. B., Lee, G. \& Selkoe, D. J (1987) Gene dosage of the amyloid beta precursor protenn in Alzheimers disease. Science $\mathbf{2 3 8}$. 669-671

Ptashne, M (1988). How eukaryotic transcriptional activators work. Nature 335, 683-689.

Rennert, P. D \& Heinrich, G. (1986). Nerve growth factor mRNA in brain: localization by in situ hybridization. Biochemical and Biophysical Research Communications 138, 813-818

Reynolds, G. P. (1988). Post-mortem neurochemistry of schizophrenia. Psychological Medicme 18, 793-797.

Roberts, G. W. (1988). Abnormalities in brain structure in schizophrena. Current Opmion in Psychiatry 1, 83-89.

St George Hyslop, P. H., Tanzi, R. E., Polınsky, R. J., Neve, R. L, Pollen, D., Drachman, D.. Growdon, J., Cupples, L. A., Nee, L., Myers, R H., O'Sullivan, D., Watkins, P. C., Amos, J. A., Deutsch, C. A., Bodfish, J. W., Kinsbourne, M., Feldman, R. G., Brunı. A . Amaduccı, L., Foncin. J.-F \& Gusella, J. F (1987) Absence of duplication of chromosome 21 genes in familial and sporadic Alzheımer's disease. Science 238, 664-666.
Sajdel-Sulkowska, E. M. \& Marotta. C. A. (1984). Alzheımer's disease brain: alterations in RNA levels and in a ribonucleaseinhıbitor complex. Science 225, 947-949.

Schlief, R. (1988) DNA binding by protenns Science 241, 1182-1187. Sutcliffe, J. G. (1988). mRNA in the mammalian central nervous system. Annual Revtew of Neuroscience 11, 157-198.

Tanzi, R. E., Bırd, E. D., Latt, S. A. \& Neve, R. L. (1987). The amylond beta proten gene is not duplicated in brains from patients with Alzheimer's disease Science 238, 666-669.

Valentino, K. L., Eberwine, J. H. \& Barchas, J. D., (eds.) (1987). In situ Hybridization: Applications to Neurobiology Oxford University Press: New York.

Weatherall, D. (1987). Molecular and cell bıology in clinical medicine: introduction. Brtish Medical Journal 295, 587-589.

Worley, P. F., Baraban, J. M. \& Snyder, S H. (1987). Beyond receptors: multuple second-messenger systems in brain. Annals of Neurology 21, 217-229.

Yanofsky, C. (1988). Transcription attenuation. Journal of Biological Chemistry 263, 609-612.

Yen, T. J., Machlın, P. S. \& Cleveland, D. W. (1988). Autoregulated instability of beta-tubulin $m$ RNAs by recognition of the nascent amino-acid termınus of beta-tubulin. Nature 334, 580-585. 